\title{
Internet and Culture
}

\author{
Marc Verboord and Susanne Janssen, \\ Department of Media and Communication, Erasmus University Rotterdam, The Netherlands
}

\begin{abstract}
The increased use of the Internet since the late 1990s has had a large impact on how arts and culture products such as films, books, cds, museum exhibitions, etc., are produced, distributed, acquired, and received. This article aims to discuss some of the most relevant developments in the study of the Internet's relation to arts and culture from a social-scientific perspective. It focuses on: It focuses on (1) processes of producing and distributing culture (material production); (2) ways in which cultural products are classified and legitimated (symbolic production); and (3) behaviors and perceptions of cultural audiences.
\end{abstract}

\section{Introduction}

The increased use of the Internet since the late 1990s has had a large impact on how arts and culture products such as films, books, cds, museum exhibitions, etc., are produced, distributed, acquired, and received. The World Wide Web has shortened communication lines between companies and between persons, enabling global contacts to strengthen and cultural exchanges to increase. How increasing usage of Internet and other new media continues to shape our social life has been among the fastest growing topics in communication research in the past decade. The consequences for the domain of arts and culture are in some respects much debated (e.g. the controversies of illegal downloading), yet in other respects rather taken for granted (e.g. the decline of cultural authority).

This article aims to discuss some of the most relevant developments in the study of the Internet's relation to arts and culture from a social-scientific perspective. Although the focus will mainly be on those cultural artifacts and events which are classified as forms of 'art' - be it highbrow, middlebrow or popular - by legitimate experts in society, one of the conclusions of this review will be that on the Internet also new, less classifiable cultural genres emerge. Similarly, the boundaries of the Internet are not always clear, as its increased usage is accompanied by many related new media and information 


\section{Internet and Culture}

and communication technologies (ICTs) (e.g. hardware devices such as cell phones and iPod and software) which can also be object of study. This overview aims to discuss three aspects of cultural fields in which the influence of Internet is observed: processes of producing and distributing culture (material production); ways in which cultural products are classified and legitimated (symbolic production); and behaviours and perceptions of cultural audiences. In doing so, we draw upon various research perspectives, which will first be introduced in Section Research Perspectives. This article cannot claim to be exhaustive, but at the same time we point out that large parts of the territory are still unexplored. Not only does much of the current literature have a much broader take on 'culture', most of the work that does address arts and culture in a more strict sense remains largely theoretical or practical, but yet lacks empirical backup.

\section{Research Perspectives}

Internet has revolutionized (re)production, distribution and consumption of media materials in at least three important ways. First, its networked structure allows Internet users -- regardless of their status or profession -- to connect directly to almost all other Internet users and exchange media content without the intervention of professional gatekeepers. Second, Internet has incorporated technology that is both available and accessible for many Internet users, which can be applied to create, edit, upload and download all types of text-based and audio-visual content. Thirdly, Internet is increasingly seen -particularly by the most recent birth cohorts -- as the principal medium to gather information on or access to culture and entertainment at the expense of print media, radio and television. Losing the monopoly to mass production and distribution of cultural goods and weakened control over information flows have both economic and symbolic implications for cultural producers as well as consumers. At the core we find the hierarchically ordered 'cultural field' in which professionals engage in cultural production through highly institutionalized practices and logics (Bourdieu, 1993) being challenged by alternative practices. Scholars have begun to theorize and, to a lesser extent, empirically study these developments in various ways.

Within communication research we find three important perspectives. Digital inequality studies are concerned with audiences and users of ICT and Internet - more particularly who have access to new 


\section{Internet and Culture}

media and who are most likely to actually use such media for social participations (e.g. in the realm of culture). Increasingly, however, notions of 'audiences', 'users' and 'consumers' are contested for dismissing the blurring of boundaries between consumers and producers. In particular, work on peer production - or user-generated content - details the work of 'prosumers': non-professionals who create cultural content online which sometimes invokes semi-institutionalized fields on its own, such as the blogosphere (Bruns, 2008). These studies also showed that despite the wide reception and application of this user-generated content, only a small segment of the population is involved in its active creation (Van Dijck, 2009). A third and related scholarship analyses computer-mediated communication and its effects on behaviours and attitudes. While often not particularly concerned with culture, it has produced relevant insights in how more or less institutionalized forms of communication (e.g. online reviews of amateurs versus professionals) influence recipients' perceptions. The significance of expertise and authority is among the focal points -- particularly in studies on how 'collective knowledge' is produced on the Internet (e.g. online encyclopaedia Wikipedia).

Internet's economic implications with regards to arts and culture tend to diverge in two main directions: consequences for business models and for marketing strategies. Media economists (but also other publicists) have started to analyse how the cultural industries has (not) adapted to changes in the way cultural products are acquired through online outlets (e.g. illegal downloading, web stores).

At the same time, proposals for new operative business strategies are being launched which explicitly incorporate characteristics of online consumption modes, such as 'collective knowledge' production (e.g. Wikipedia) or 'crowdsourcing' (e.g. www.sellaband.com). Marketing specialists have recognized one particularly salient trait of Internet communication: the possibility to create 'word-of-mouth' effects in an online context, thereby generating a certain 'buzz' which is both perceived as authentic valorization by peers and yet can have the scale of mass advertising. This has been labelled Electronic Word-of-Mouth (eWOM). Non-institutionalized platforms for 'user-generated content' such as cultural blogs can consequently be targeted to have marketing messages distributed through bottom-up processes.

A third strand of research addresses the symbolic production of culture on the Internet. One emancipatory manifestation of such work - emphasizing how fans and other 'common' (prod)users - 


\section{Internet and Culture}

negotiate the meaning attributed to popular culture - is found within the paradigm of cultural studies. Most of this work concerns ethnographic accounts that elucidate the place of audiences in the 'convergence culture' (Jenkins, 2006), a constellation in which media are understood to fulfil increasingly similar functions for ever more indistinct social groups. As such, often social inequalities in terms of education, age or gender are argued to be no longer significant markers for taste and behaviour, and notions of cultural authority are challenged. However, studies in cultural sociology argue that Bourdieu's (1984) concept of 'distinction' may has weakened due to the ascendance of more omnivorous cultural consumption patterns - that is combining highbrow and popular culture - but cannot be completely abandoned. Popular culture has also become more institutionalized over time, and many of such off-line configurations tend to be reproduced in online contexts.

\section{Material Production and Distribution}

Most discussion on how Internet affects the world of arts and culture apparently concerns the way cultural products are produced and distributed. Illegal downloading is a major concern in the cultural industry: all cultural goods that can be electronically copied (music, film, photographs, books) are increasingly being disseminated without permission of the original cultural producers who consequently suffer loss of revenue (Levine, 2012). Yet also legal ways in which products find their way to audiences (via web stores or intermediary sites such as YouTube or Flickr) affect how the cultural industry as mediators are being sidetracked. Although the disruption of traditional business models in the cultural industries has prompted many observers to signal the start of a completely new era -- for the worse or for the better -- in many ways there is also continuation of old discussions.

In mid-twentieth century the introduction of 'reproduction' of recorded images (film, television) and sounds (music), aroused strong debates on what constitutes 'art' and to what extent cultural products could be 'commodified' in an almost industrial way (e.g. Frankfurter Schule). Despite reproducible products becoming key ingredients in the diets of many cultural audiences in the second half of the century -- and thus losing most of their controversy --, criticism never completely disappeared. While many sociological and media/cultural economic studies pursue objective analysis of production practices and their implications, normative perceptions on cultural value or the 


\section{Internet and Culture}

functioning of the industry are still widely spread. Examples of such expressions are for instance found in critiques on how book publishing threatens standards of literary culture, or in the political economist's concerns that the corporations involved in cultural production reduce the variety of opinions and tastes through their shaping of news, entertainment, and other media expressions (Bagdikian, 2004).

These discussions resonate in theoretical publications on cultural production in the digital age which tend to take two competing perspectives. Both of them, however, appear to draw on three underlying argumentative dimensions: economic, artistic and moral considerations. Among Internet's criticasters, a first group emphasizes the destructive effects that Internet-related practices have on the existing cultural industries. Their main argument is that the 'free riding' behavior which Internet provokes will decrease incomes such that it will ultimately drive cultural producers out of business (e.g. Levine, 2012). This view is countered, however, by various theorists who argue that Internet also offers new opportunities for business as producers can take advantage of 'collective wisdom' production and user-generated content to gain more insight in consumer demands (e.g. Tapscott and Williams, 2008).

A second type of arguments concerns the 'quality' of the output. Antagonists mainly lament the decline of artistic - but also journalistic - quality and diversity in content that Internet allegedly induces. In their view, 'user-generated content' does not meet the standards of institutionally produced content, due to the absence of professional gatekeepers, which would degrade the available supply (e.g. Keen, 2007). Again, opposite viewpoints are taken. Particularly in the domain of news production, some argue that 'user-generated' content increases diversity of voice, and as such contributes to a multiform society. In addition, Chris Anderson (2006) in his book The Long Tail points at increasing diversity at the aggregate level. Centralizing the storage and searchability of cultural products in an online context (e.g. a web store like Amazon) enables consumers to discover products out of the mainstream, and, consequently, producers to exploit niche markets which were not profitable before the digital age. He argues that this may very well lead to the end of the 'blockbuster economy'. 


\section{Internet and Culture}

Finally, there is a third group of scholars that stresses more moral and ethical aspects of Internet, particularly the issue of copyright and ownership of cultural content. Violation of copyright is one of the main concerns of the industry with regards to Internet distribution of culture -- and this obviously includes also the creators of culture themselves (the artists). Besides the loss of economic revenue, infinite reproduction and unofficial distribution via new media also invokes a moral contemplation on the value of 'creation'. Artists who take considerable pains in creating new works of art see themselves confronted with audiences who increasingly expect free and instant satisfaction of their individual cultural wants - disregarding the artists' investments. The advent of 'user-generated content' fuelled this debate on copyrights, as we find also theorists who argue that taking existing content to re-create and re-mix cultural expressions is not very different from traditional artists finding inspiration in folk tales or using samples and quotes (Lessig, 2008). On the most fundamental level, however, copy right discussions address the question whom the current system truly benefits most -- and whether that is changing: the media conglomerates that do most investments, the artists who are the source, and/or the art that seeks innovation.

Many of these issues regarding production and distribution currently remain unresolved, as empirical evidence is often lacking or hard to find (Curran et al., 2012: 69ff). For instance, there is of yet no clear evidence that The Long Tail has indeed become such profitable market niche that it inflicts death on the blockbuster. And while illegal downloading in all likelihood affects the cultural industries, these industries have also been slow to innovate: record companies have been retailing their back catalog for years (via the cd); film companies have increasingly centered their production around formulaistic high-spectacle blockbusters. Meanwhile many new business models - such as crowdsourcing models or 'value-based pricing models' - are still too young for definite conclusions (Wikström, 2009). And lastly the copyright wars are not yet decided - despite new initiatives such as 'blanket protection' in which the rights to distribute products are granted to Internet service providers in exchange for payment - being underway (Levine, 2012).

Meanwhile new media are increasingly applied within the marketing of cultural products. In the film industry, trailers of new movies are increasingly disseminated via the larger film blogs that in many ways have taken over the dominance of trade journals in breaking news and reporting on the 


\section{Internet and Culture}

movie scene. For the book industry, Thompson (2010: 243ff) shows how author tours and print advertising are increasingly being replaced by online advertisements and building word of mouth via the blogosphere. Getting positive reviews are not the aim. Instead, publishers target a relatively small group of influential bloggers in order to create a certain 'buzz' which can translate in off-line demand.

\section{Symbolic Production}

Consensus on what cultural manifestations are artistically valuable or important - in other words, are legitimate - has traditionally been reached through highly hierarchical systems. Within thematically organized domains or fields, institutions operated through agreements on how production and distribution practices should be performed (Bourdieu, 1993). Both institutions and individual agents within these institutions nevertheless compete for cultural authority through securing and expanding their influence in the field, as higher levels of assigned expertise translate in more status. At the same time, the agency of audiences - when contributing to the process of legitimation - has been more of a receptive nature than a productive one.

Yet value attribution to cultural products is not hierarchical per definition. Legitimation should be seen as a social process, since institutional agents rely heavily on having an audience that accepts their selections and evaluations, or in other words puts 'belief' in them (Bourdieu, 1993). In the traditional system, print media such as newspapers, opinion magazines and academic journals served as outlets for institutional agents, stressing the top-down process of legitimation by its unidirectional character from producer to consumer. The reason for this was twofold: (1) the selection of persons who could enter the field was confined to those showing the ideas already dominant in the field and (2) the ideas of these agents working in the media field on what makes legitimate culture resembled the ideas of their audiences since they were largely recruited from the same social ranks (Bourdieu, 1993).

The arrival of the Internet has led to less hierarchical systems of classifying information -among which evaluations of culture -- due to its specific characteristics, as is theorized by Verboord (2010; 2013). The open nature of the Internet has enabled cultural audiences without institutional ties to engage in discussions of quality or value beyond merely reacting on professional critics. Not only do audiences have the means to be faster to evaluate (as publications of traditional print media are often 


\section{Internet and Culture}

still slowed down by editorial checks and publishers' time to process), they also publish outside traditional institutional settings. Particularly within popular culture, discussion forums and consumer review sites circumvent professional critics and authorities. Often, evaluating culture is also more explicitly linked to the purchasing of cultural goods (e.g. web stores such as Amazon) and is rescaled from a few extensive, in-depth evaluations to a large number of short, sometimes ill-written, biased or even invalid comments (cf. David and Pinch, 2006). Symbolic production in the cultural field has thus been restructured in the sense that dispersion of audience attention, larger diversity of voice, uneven quality in writing and argumentation has made it harder for cultural critics to solidify their authority. In this fast changing media landscape, media outlets and the critics therein, have more and more difficulty to stay connected to specific audience groups. This declining homology between media and audiences is particularly salient on the Internet which puts considerable pressure on the legitimacy of critics and related institutional agents. This does not mean expertise is longer important, however. The empirical results of Verboord (2010) demonstrate that expert critics are still valued higher than online critics. Similarly, studies in computer-mediated communication show that textual properties and communication tactics are highly important to be considered as prominent and 'useful' reviews (e.g. Otterbacher, 2011). Traits associated with professionalism such as correct spelling and high levels of argument density are thus used to filter out credible information in the enormous online supply. Still, the ascendance of peer-produced content challenges the hierarchical model of cultural evaluation, although it still remains in use, but particularly stimulates the use of popular aesthetics as the standard form of evaluative discourse (Verboord, 2013).

It remains to be seen if symbolic production has become more democratic and multiform in the digital age. Traditionally, cultural genres with more social status tend to show more inequalities in terms of gender, ethnicity and social class. An exploratory analysis of the fiction book output in one month in the United States showed that female authors generally were more often reviewed on Amazon and social network Goodreads than male authors, whereas print media showed no significant difference (Verboord, 2011). This result may however be typical for the book market in which women form a large part of the readership. 


\section{Internet and Culture}

\section{Audiences}

\section{Cultural Participation}

Much of the reduction in control that cultural producers used to have in producing and disseminating content has accrued to audiences. Provided that one has the access and the digital skills to go online, it is often easier, faster and cheaper to purchase products and tickets, find information, contact likeminded persons, share opinions and emotions on experiences, etc. in this digital environment. Representative studies into the way cultural participations are affected by online mediation are rare, however. One of the few attempts to map cultural participation through new and traditional media is conducted in 2009 at the Netherlands Institute for Social Research for a representative sample of the Dutch population, aged 18 years and older (Sonck and De Haan, 2012). Contrasting popular culture (pop music, film) and traditional culture (theater, visual arts, cultural heritage, classical music) in both receptive and more active modes of participation, they show huge discrepancies across activities and cultural forms. Overall, old media are still used more often than new media. Even among the youngest age group - 18-34 - new media have a complementary rather than a substitutional role.

In absolute terms, Internet is most often used for finding information: more than $40 \%$ of the population has ever looked for information on pop music, film or theater. For the other art forms this percentage lies between 10 and 20\%. About a quarter of the population buys tickets and/or recordings of pop music or film via the Internet. Still, only with regards to pop concert tickets, online buying has actually surpassed off-line buying. Purchasing highbrow culture via the Internet is mainly restricted to buying theater tickets (34\% vs 36\% off-line). Actual (mediatized and receptive) cultural participation - viewing and/or listening to objects and recordings - is predominantly done via audiovisual media. Online participation amounts to almost $20 \%$ for all cultural forms, except classical music (only $5 \%$ ) and pop music (almost 30\%). Despite web2.0 tools becoming increasingly available, active forms of participation are not widely spread. Creating and sharing cultural content were established for a third of the Dutch, but this includes photographs and diary fragments which may be uploaded just for friends. Only $5 \%$ reported to ever have posted messages on arts and culture. 


\section{Internet and Culture}

These online participation trends - though perhaps partly superseded by advancing ICTs and media logics - reveal the contextual imperative of the social shaping of technology. Online participation variably relates to particular issues such as scarcity (ticket purchase for performances), searchability (information), replicability (music files), or archivability (cultural heritage, visual arts). Contrary to what some Internet gospellers state, simply having the opportunity to use the Internet for a particular purpose is clearly not enough to propel such usage. Dependent on their skills, attitudes and incentives, audiences pursue applications that enable them to efficiently find desired gratifications and affordances. Which online services come into vogue is difficult to predict. Successful online services seem to originate more often from outside traditional cultural production and benefit particularly popular culture. Although producers of highbrow products similarly need to relate to their clientele, this audience group is generally smaller, older and more aligned to institutionally rather than peer produced expertise. As a result, many of these producers still take the tradition as the point of reference, such as virtual museums which are principally created to make collections and associated documentations more accessible, and secondly want to provide an entertaining and educational experience (Styliani et al., 2009).

Whereas such highbrow endeavors to reach out to audiences still command high levels of control, more popular culture has generated mostly interactive platforms where audiences are also enabled to become creators themselves. Video Web site YouTube is perhaps the most used and most famous form of such participatory culture: about half of its contents appears to be user-generated (Burgess and Green, 2009). The website exemplifies the notion of 'convergence culture' through its integration of different forms of media (television, film, music, photographs), but just as much in how culture is represented. Next to the wide circulation of original content produced in cultural industries' formats, many alternative versions of such materials are available in various degrees of editing, mixingup, animation, imitation, etc. (Burgess and Green, 2009: 42-43). Such media work of (semi-)amateurs consequently generates new, at times unclassifiable, genres outside of institutionalized settings. It is here where the cultural participation of audiences comes closest to reordering the status quo of cultural fields. 


\section{Internet and Culture}

\section{Cultural Information Regimes: Between Mass and Niche}

The experiential nature of arts and culture together with the infinite variety of products implies that information on cultural products comprises a double-edged uncertainty. Since audiences can only evaluate products after consuming and experiencing them, they do not know whether they choose the 'right' product before acquisition. Consequently, producers do not know what products will become successful among audiences. Several information regimes are applied to reduce uncertainty. The most traditional, highbrow oriented, regime of cultural classification was already discussed in the previous section. On the Internet, market information regimes which inform producers and consumers on popularity appear more important, however. It is almost standard practice on the web to inform Web site visitors about the popularity of the Web site itself, particular texts on that site (e.g. by letting visitors assess the usability, or give a Facebook like), or products on the site (e.g. book sales on Amazon.com; number of previous downloads).

The potential power of online disseminated market information was demonstrated in a webbased experiment by Salganik and Watts (2008) that created parallel online universes in which the same (relatively unknown) pop songs were attributed different popularity scores by the researchers. Once consumers could start to listen to the song corpus and download their preferred tracks, the demand curve developed consistently in favour of those songs which had the largest (manipulated) download scores from the start. Yet if the same songs in a different online universe had been flagged as not been downloaded a lot, demand did not grow hard. This result underscores the more general observation that although Internet has increased the supply of media content to almost infinite proportions, demand appears to be highly concentrated because information overload is an impetus to use filters such as popularity markers.

Despite these results, empirical studies suggest that interpersonal ties still prevail above Internet sources when looking for cultural information (Kayahara and Wellman, 2007). While Internet is frequently used to find detailed information on particular products or events, recommendations on which artists or products to look for in the first place often still comes from the personal off-line network. What is more, despite technology use to find new music being highly diversified, it does not seem to help more people to become opinion leaders in their social circles nor online (Tepper and 


\section{Internet and Culture}

Hargittai, 2009). In a similar vein, participation in social network sites mainly follows from off-line contacts or interests, making it easier to connect to like-minded persons, but not necessarily leading to new friendships (Baym and Ledbetter, 2009). Still, there is increasing evidence that social media are reshaping cultural consumption practices (Dewan and Ramaprasad, 2012).

\section{Discussing Culture: The Voice of the Consumers}

Besides transforming systems at the societal level - such as access to cultural content and currency of information regimes - user-generated content is also strongly associated with new ways in which content is discussed and deliberated at the level of individual consumers of (popular) culture. Again, partly this follows from increased network opportunities. Internet has provided fans of popular culture with the means to (virtually) meet like-minded persons and share thoughts, interpretations, and evaluations on specific web forums. To be sure, the rise of fan culture has been underway since the breakthrough of popular culture in the 1960s, but from the start Internet proved to be an important facilitator of communication. Having started out as a domain for 'geek culture' in which mostly 'techsavy' males propagated genres such as science fiction and alternative rock, it has widened substantially. Moreover, online fan culture has developed a voice which exceeds in-crowd discussions on trivial content details. Particularly, Jenkins (2006) provides an account - within the broader theoretical framework of media convergence - of how new media enable fans to influence practices of corporate producers. Fans contribute to the producers' deeper understanding of how their work is interpreted and evaluated, and, ultimately, how program loyalty can be achieved. Interactive television formats in which viewers can for instance vote in talent shows accommodate this connection to the fan base. At the same time, some content fans create online may harm the interests of producers. Examples concern new stories on Harry Potter which violate copyright laws or the emergence of 'spoiler' sites on which fans try to disclose television content before it is officially broadcasted. Although originally many of such practices are the work of small groups situated in relatively obscure online communities, grassroots convergence has empowered fans through collective intelligence. Interactivity first stirs the depths and intensity of communication within such communities. Subsequently, the content at stake -- if it gains sufficient momentum -- gets picked up by outlets higher in the media hierarchy, after which it may 


\section{Internet and Culture}

continue to be circulated until it reaches mainstream audiences. One important remark needs to be made: while such bottom-up processes do allow new products or creators to rise to stardom (e.g. rock band Arctic Monkeys via MySpace), most participations reported in these fan studies still concern popular culture produced in the cultural industries. Moreover, this is line with results from other studies into participatory culture such as YouTube: user-created content augments diversity yet audience attention is most drawn by what originated from traditional media (Burgess and Green, 2009).

\section{Prospects}

Despite the rapidly growing literature on new media and Internet, research which focuses on their impact on arts and culture remains relatively limited and scattered across disciplines. Internet's novelty, omnipresence and fast pace at which it penetrated Western society not only spurred a great variety of perspectives, but also stimulated theory to regularly develop without empirical falsification.

More empirical evidence for theorized effects is needed. Part of such empirical underpinning would entail employment of multiple methods and cross-disciplinary perspectives. For instance, studies into online fan culture remain persistently qualitative in nature - thereby preventing generalization of findings. At the same time, research into effects of online reviews largely relies on quantitative measures, often based on student experiments.

Connecting different research perspectives thus appears to be one of the major challenges for the study of arts and culture in the digital age. Such interconnections help to better understand some of the paradoxes that emerge from the current literature. For instance, how the creation of user-generated content has reversed many cultural flows from top-down to bottom-up, but at the same time most cultural content which is circulated online still springs from the cultural industries (either in original or re-mixed versions) and only a limited number of Internet persons can actually be called 'produsers'. Or the observation that the Internet facilitates the convergence of media, cultural genres, and even consumption and production practices, yet what is actually consumed and produced is subject to increasingly larger fragmentation and individualization. Also, the role of social network sites (e.g. Facebook) in taste formation, the use of technology to recommend consumers mainly cultural products 


\section{Internet and Culture}

very similar to what they purchased before, and the future of physical cultural outlets in an increasingly digitalizing world are important themes for future research.

See also: Computer Mediated Communication; Cultural Mediators and Gatekeepers; Cultural Production in Networks; Culture, Production of: Prospects for the Twenty-First Century; Markets: Artistic and Cultural; New Media and the Digital Divide; Symbolic Boundaries; Video Cultures: Television

\section{Bibliography}

Anderson, C., 2006. The Long Tail. Why the Future of Business is Selling Less of More. Hyperion, New York.

Baym, N.K., Ledbetter, A., 2009. Tunes that bind? Predicting friendship strength in a music-based social network. Information, Communication and Society 12, 408-427.

Bourdieu, P., 1984. Distinction. A Social Critique of the Judgment of Taste. Routledge and Kegan and Paul Ltd, London.

Bourdieu, P., 1993. The Field of Cultural Production. Polity Press, Cambridge. Bruns, A., 2008. Blogs,

Wikipedia, Second Life and beyond: From Production to

Produsage. Peter Lang, New York.

Burgess, J., Green, J., 2009. YouTube. Online Video and Participatory Culture. Polity Press, Cambridge.

Curran, J., Fenton, N., Freedman, D., 2012. Misunderstanding the Internet. Routledge, London.

David, S., Pinch, T., 2006. Six degrees of reputation: the use and abuse of online review and recommendation systems. First Monday 11 (3). http://www. firstmonday.org/issues/issue11_3/david (accessed 15.11.07.).

Dewan, S., Ramaprasad, J., 2012. Music blogging, online sampling, and the Long Tail. Information Systems Research. First published online 13 February 2012, as. http://dx.doi.org/10.1287/isre.1110.0405.

Jenkins, H., 2006. Convergence Culture. Where Old and New Media Collide. New York University Press, New York.

Kayahara, J., Wellman, B., 2007. Searching for culture - high and low. Journal of Computer-Mediated Communication 12, 824-845.

Keen, A., 2007. The Cult of the Amateur. How Today's Internet is Killing Our Culture. Doubleday/Currency, New York.

Lessig, L., 2008. Remix. Making Art and Commerce Thrive in the Hybrid Economy. Penguin, London.

Levine, R., 2012. Free Ride. How the Internet is Destroying the Culture Business and How it Can Fight Back. Vintage, London.

Otterbacher, J., 2011. Being heard in review communities: communication tactics and review prominence. Journal of Computer-Mediated Communication 16, 424-444.

Salganik, M.J., Watts, D.J., 2008. Leading the herd astray: an experimental study of self-fulfilling prophecies in an artificial cultural market. Social Psychology Quarterly 71, 338-355.

Sonck, N., De Haan, J., 2012. De Virtuele Kunstkar. SCP, The Hague.

Styliani, S., Fotis, L., Kostas, K., Petros, P., 2009. Virtual museums, a survey and some issues for consideration. Journal of Cultural Heritage 10, 520-528.

Tapscott, D., Williams, A., 2008. Wikinomics: How Mass Collaboration Changes Everything. Atlantic Books, London.

Tepper, S.J., Hargittai, E., 2009. Pathways to music exploration in a digital age. Poetics 37, 227-249.

Thompson, J.B., 2010. Merchants of Culture. The Publishing Business in the Twenty- First Century. Polity Press, Cambridge.

Van Dijck, J., 2009. Users like you? Theorizing agency in user-generated content.

Media. Culture and Society 31, 41-58.

Verboord, M., 2010. The legitimacy of book critics in the age of the Internet and omnivorousness. European Sociological Review 26, 623-637. 


\section{Internet and Culture}

Verboord, M., 2011. Cultural products go online. Comparing the Internet and print media on distributions of gender, genre and commercial success. Communications 36, 441-462.

Verboord, M., 2013. The impact of peer-produced criticism on cultural evaluation. A multi-level analysis of discourse employment in online and offline film reviews. New Media and Society. First published on 3 July 2013 as. http://dx.doi.org/10. 1177/1461444813495164.

Wikström, P., 2009. The Music Industry: Music in the Cloud. Polity Press, Cambridge. 